\title{
Comparison of type I collagens and MMP-2 proteins in temporomandibular joint of young and old mice
}

\author{
M. Demir ${ }^{1}$, M.K. Tümer ${ }^{2}$, M. Çiçek ${ }^{1}$, M. Uysal ${ }^{3}$, A. Yoldaş ${ }^{1}$, A. Doğaner ${ }^{4}$ \\ ${ }^{1}$ Department of Anatomy, Faculty of Medicine, Kahramanmaras Sütcü Imam University, Kahramanmaras, Turkey \\ 2Department of Oral and Maxillofacial Surgery, Faculty of Dentistry, Gaziosmanpasa University, Tokat, Turkey \\ ${ }^{3}$ Department of Anatomy, Faculty of Medicine, Gaziosmanpasa University, Tokat, Turkey \\ ${ }^{4}$ Department of Biostatistics, Faculty of Medicine, Kahramanmaras Sütcü Imam University, Kahramanmaras, Turkey
}

[Received: 24 July 2017; Accepted: 5 October 2017]

Background: The effects of ageing on the histopathological changes of temporomandibular joint (TMJ) and the existence and age related alterations of immunochemical expressions of type / collagen and matrix metalloproteinase-2 (MMP-2) proteins was aimed to be displayed.

Materials and methods: In this study, 14 Balb/C type white mice (50-80 g) were included. Groups were organised as group 1 - 2-month-old young animals $(n=7)$ and group 2 - 18-month-old old animals $(n=7)$. Of the paraffin embedded tissues 4-5 $\mu$ m thick sections were taken and immunohistochemical stainings of haematoxylin-eosin, type-1 collagen and MMP-2 were performed. Results: Collagen bundles showed sagittal and oblique localisations in the young mice, which were comprised of compact collagen bundle layers positioned alternately. While collagen bundle fragmentation was observed in the disks of old mice, some disk regions showed ruptures. In the old mice a decrease in blood vessels, structural impairments and dilatation in arterioles and venules were detected. In the TMJ tissues of the young mice type I collagen and MMP-2 expressions were increased, while they were decreased in old mice. In the MMP-2 H-score evaluation young mice showed significant increase compared to the old mice.

Conclusions: Occurrence of degenerations in the collagen structure of TMJ and decimation in the matrix metalloproteases were observed with age. (Folia Morphol 2018; 77, 2: 329-334)

Key words: temporomandibular joint, type I collagen, MMP-2, matrix metalloproteinase-2, immunreactivity, ageing

\section{INTRODUCTION}

Temporomandibular joint (TMJ) is an element of the stomatognathic system comprised of chewing muscles, muscles around the head and neck, ligaments, teeth, cheek, lip and salivary glands, and is the most complicated bone of the human body. TMJ is located between the mandibular fossa below the temporal bone and the mandibular condyle just in front of the external auditory canal, as a diarthrodial joint. It is a compound joint with a slide axis making hinge and slide movements [11]. The bone fragments of the TMJ are covered with a thin fibrous capsule. Extracellular matrix of the fibrocartilage disc is usually composed of type I

Address for correspondence: Dr. M. Demir, Department of Anatomy, Faculty of Medicine, Kahramanmaras Sütcü Imam University, 46000 Kahramanmaras, Turkey, tel: +90-505-938-7311, e-mail: mdemir2779@gmail.com 
and type II collagen. There are elastic fibres in each part of the disc. Owing to its unique structure, the disk can dissipate and relieve extreme forces. It shows viscoelastic properties under weights where the arrangement of collagen bonds strengthens its resistance [3]. Temporomandibular joint disorders (TMD) are disorders of the joint function that occur due to intra-articular or extra-articular pathologies. Generally, the age of the onset of the disease varies between 18 and 26, while the age of seeking medical advice varies between 20 and 50 . TMD is a clinical entity characterised by pain in the jaw joint, noise (creep or click) and irregular jaw movements, and is one of the most difficult causes of maxillofacial pain in terms of treatment [6]. TMD is common and its prevalence ranges from $5 \%$ to $16 \%$. It is $4-6$ times more common in women and its incidence increases with age [5]. Among the major effects of ageing on the organism, changes in the oral cavity and therefore in the tissues surrounding it are very important. Along with ageing, the calcified tissue is reduced in all bones, often in women, resulting in porosity and increased brittleness of the bones. Moreover, in the elderly, the blood flow in the maxilla and mandible decreases [1]. Alterations in the mouth structures due to ageing, by affecting the TMJ over time, cause some structural and functional changes. In the temporal bone, events such as deepening of the glenoid pit or flattening of the articular eminence occur due to adaptive changes, not degenerative. With advancing age, the articular disc slenderizes and the flattening of the joint surfaces and calcifications in the nodal pattern become common. In the elderly, due to the discordance of the articular disc and the condylar movements, faint to loud noises can be heard while opening the mouth. In addition, traumatic mandibular subluxation or dislocation may easily occur, and fractions in the thinned condylar structure are frequently encountered. Ankylosis in TMJ usually develops due to pyogenic infections that arise following a severe mechanical trauma [9]. Factors such as incorrect dental restorations, excessive tension and relaxation in the chewing muscles, and bruxism also cause alterations in the occlusal surfaces of the teeth, thus leading to the degeneration of the conformity of the lower and upper jaw teeth in the closing position. This leads to chronic trauma in TMJ, and thus, to myofascial pain and dysfunction syndrome [4]. Osteoarthritis, a degenerative joint disorder, causes crepitation, tenderness, pain, and, rarely, movement restriction in TMJ. $20 \%$ of the polyarticular rheumatoid arthritis cases have TMJ involvement. In this case, inflammatory lower jaw movements in the joint are restricted [14]. In toothless older patients with Costen's syndrome, as a consequence of mouth being over-closed, with the displacement of the condyle in a posterior-superior direction, may cause symptoms such as headache, dizziness, ear pain, tinnitus and heartburn [9]. In people over 50 years of age, osteoarthritis is often more common in the jaw joint, which causes facial pain and noise in the TMJ. Especially, in the osteoarthritis seen in older ages, the TMJ is also affected as well as other joints of the body [12, 19]. Matrix is the structure composed of fibres and extracellular substance. Collagen, hyaluronic acid and proteoglycans are large proteins that constitute the matrix. Collagen fibres are the most abundant proteins of the body that increase durability [15].

In this study, it was aimed to investigate the histopathological impact of ageing on the TMJ, and the immunohistochemical expression status and age related-alteration of the type I collagen and matrix metalloproteinase-2 (MMP-2) proteins.

\section{MATERIALS AND METHODS}

\section{Animal selection}

This study was conducted in the Department of Experimental Medicine Research, Gaziosmanpaşa University with the approval of the local ethics committee (HADYEK-28). Fourteen Balb/C female white mice (50-80 g) were used in this study. Animals were divided into two groups, which were arranged as group 1, 2-month-old animals group ( $n=7)$, and group 2, 18-month-old animals group $(n=7)$. Mice were kept at room temperature $\left(22 \pm 1^{\circ} \mathrm{C}\right)$ and in $40-50 \%$ humidity before the procedure. Lights were arranged for $12 \mathrm{~h}$ of daytime and $12 \mathrm{~h}$ of nighttime. Their eating and drinking were not restricted. Mice were kept under surveillance for a week and their physical examinations were performed on a daily basis.

\section{Sample collection}

Healthy mice were euthanised with exsanguination under ketamine/xylazine $(50 / 10 \mathrm{mg} / \mathrm{kg})$ anaesthesia. The temporomandibular joint including the ramus mandibular and part of the temporal bone of the mice was removed as a block to preserve the integrity and transferred to a $10 \%$ EDTA solution to use for immunohistochemical and histological evaluations. 


\section{Histopathological evaluation of the TMJ}

Tissue samples were maintained in the EDTA solution until ready for sectioning. Tissue samples were embedded to paraffin blocks following routine histological examinations. Then, $4-5 \mu \mathrm{m}$ sections were taken from paraffin-embedded tissue samples and stained with haematoxylin-eosin (H\&E). Slides were evaluated under Zeiss Axio Lab A1 light microscope.

\section{Immunohistochemistry}

The 4-5 $\mathrm{mm}$ sections taken from the paraffin blocks were transferred to polylisin containing slides. After dehydrating the deparaffinised tissues by immersing though gradual alcohol series, the samples were removed to distilled water and boiled for 5 min for antigen retrieval in a citrate buffer $(\mathrm{pH}=6)$ with a microwave $(600 \mathrm{~W})$. In order to prevent the endogen peroxidase activity they were treated with $\mathrm{H}_{2} \mathrm{O}_{2}$. Then, to prevent background staining, after being treated with the Ultra $\mathrm{V}$ Block (Ultra $\mathrm{V}$ Block, TA-125-UB, Thermo Fisher Scientific Inc., USA) solution they were incubated with the primary antibody (Rabbit polyclonal to Aquaporin 1, Abcam, AB110186, Cambridge, UK; Rabbit polyclonal to Aquaporin 3, Abcam, AB34710, UK) for $60 \mathrm{~min}$. Then, following the applications of the secondary antibody for $30 \mathrm{~min}$ biotinylated anti-mouse IgG, Diagnostic BioSystems, KP 50A, Pleasanton, USA), the streptavidin horseradish peroxidase for $30 \mathrm{~min}$, 3-amino-9-ethyl carbazole chromogen, contrast staining was performed with Mayer's haematoxylin. On the tissues prepared as negative controls, all steps were performed similarly, except that instead of primary antibody, phosphate buffered saline (PBS) was used. Tissues, applied with PBS and distilled water were covered with the proper solution. Prepared slides were appraised and photographed under research microscope (Zeiss Axio Lab A1). The evaluation of the immunohistochemical labelling was performed using the $\mathrm{H}$-score analysis [8]. Type-1 collagen and MMP-2 immunoreactivity intensities were appraised semi-quantitatively according to the intensity scores of 0 (none-staining), $1+$ (weak but recognisable staining), $2+$ (moderate or distinct staining), and $3+$ (strong staining). For each tissue, by calculating the total of the percentages of the cells according to their staining intensities, an $\mathrm{H}$-score value was obtained. After that, the weighted intensity of the staining was multiplied with this value using the $\mathrm{H}$-score $=\Sigma \mathrm{Pi}(\mathrm{i} 1+)$ formula, where ' $\mathrm{l}$ ' represents the density scores and ' $\mathrm{Pi}$ ' represents the relative percentage of cells. Each slide was evaluated under light microscope ( $\times 40$ magnification). The percentage of cells at each density was determined by two investigators, at different times and without the knowledge of the type or origin of the tissues. The average of both observers' scores was used.

\section{Statistical analysis}

Fisher Exact test was used for statistical analysis of categorical variables. Distributions of variables were expressed in percentages and frequencies. Values of $p<0.05$ were considered statistically significant. Data analysis was performed using SPSS 22.0 (IBM SPSS for Windows version 22, IBM Corporation, Armonk, New York, USA).

\section{RESULTS}

\section{Histological findings}

The histological structures of the TMJs of the young and old animals were photographed (Fig. 1). Histopathological evaluation showed collagen bundles in young mice that were located sagittal and oblique, and comprised of layers of compact collagen bundles placed alternately with each other. In the discs of old mice, at first, collagen bundle disruption was observed, but in some disc regions, tears were found. Although blood vessels were apparent in young mice, in old mice, less blood vessels, structural deterioration, and dilatations in arterioles and venules were identified. In young mice, the articular surface was intact and appeared as a smooth outline. On the other hand, in old mice, on the joint surface, disintegrations and lacerations possibly due to calcification were observed. The joint surface in young mice exhibited a wavy appearance, and differentiated fibroblasts were detected under this surface. Oval cells showed sporadic and irregular distribution. Moreover, in old mice, fissures extending from the joint surface to cartilage layer and degeneration in the deep layers near the calcified cartilage were described. Splits and ruptures leaving calcified strata were reported in many parts of the joint cartilage. Evident proliferations in the cartilage margin were also observed.

\section{Immunohistochemical findings}

In the TMJ tissue sections of old and young mice, type I collagen and MMP-2 proteins were stained immunohistochemically. No immune reactivity was observed in the stainings of the negative controls. Results were evaluated semi-quantitatively and are 

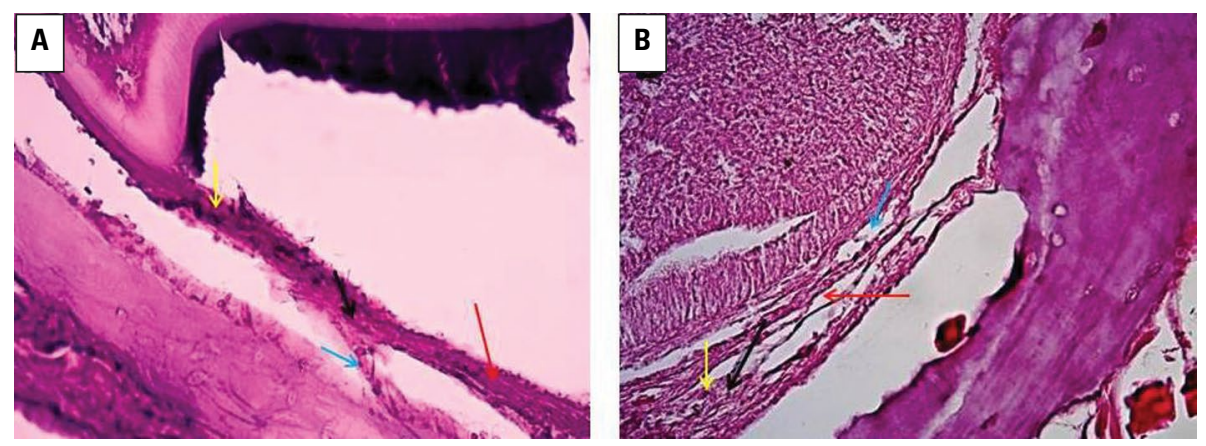

Figure 1. Haematoxylin- eosin staining, 20×. A. Young mice; B. Geriatric mice (yellow arrow — fibroblasts, black arrow — collagen fibres, red arrow — cell lines, blue arrow — blood vessels).
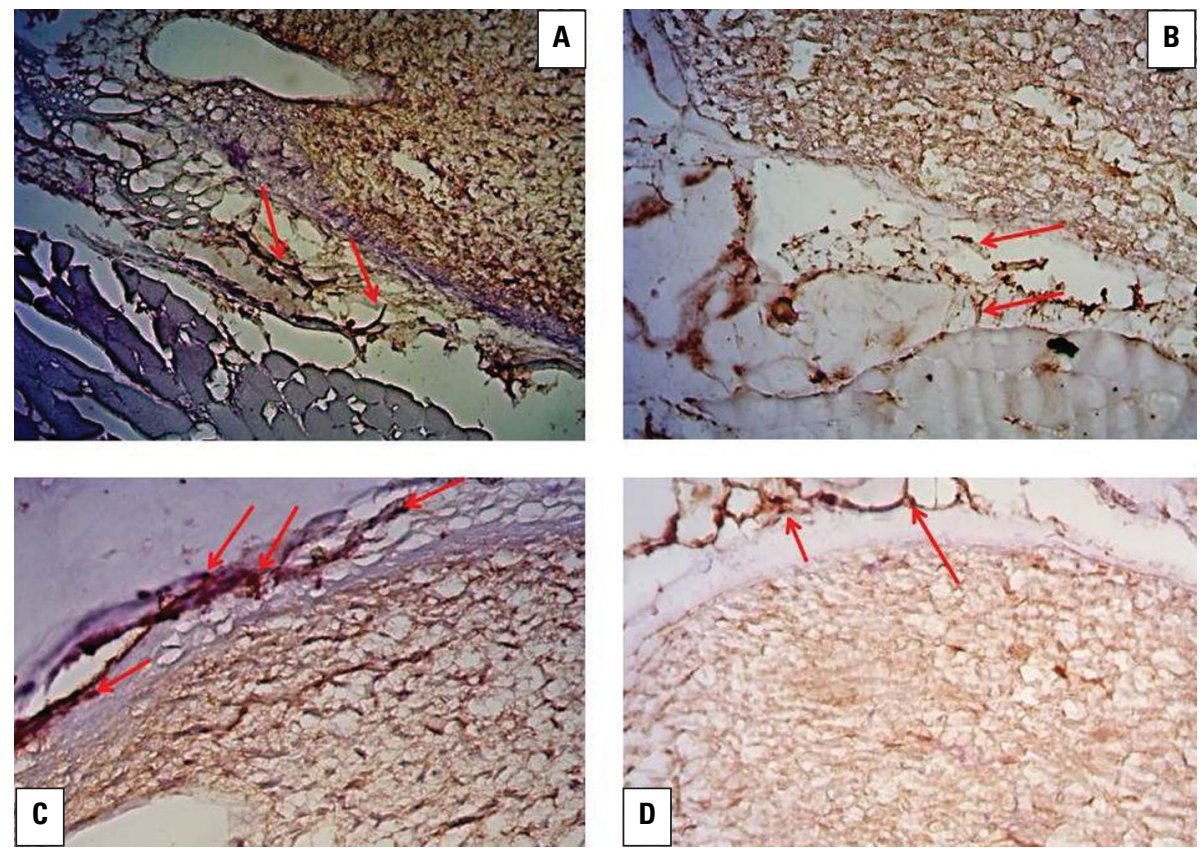

Figure 2. Immunohistochemical staining of type I collagen and matrix metalloproteinase-2 (MMP-2), $20 \times$. A. Type I collagen young mice; B. Type I collagen geriatric mice; C. MMP-2 young mice; D. MMP-2 geriatric mice.

shown in Table 1. In the TMJ tissues of the young mice, increased $(+++)$ type I collagen and MMP- 2 immune reactivity was observed (Figs. $2 \mathrm{~A} ; 3 \mathrm{~A}, \mathrm{~B})$, while in the old mice the type I collagen showed a low $(+)$ (Figs. $2 \mathrm{~B} ; 3 \mathrm{~A})(\mathrm{p}=0.001)$ and MMP-2 an average $(++)$ (Figs. 2D; 3B) $(p=0.001)$ immune reactivity (Table 1). In the H-score results of immune positive stained cartilage cells with a fibrocartilaginous structure from the synovial regions of the TMJ, the cellular MMP-2 immune reactivity was significantly higher in young mice than in the old mice (Table 2; Figs. $3 \mathrm{C}$ ) $(p=0.002)$.

\section{DISCUSSION}

Temporomandibular joint disorders are common disorders affecting the quality of life. The formation of the articular cartilage matrix includes collagen, hyaluronic acid and proteoglycans. Therefore, collagens are expected in the joint structure and the density to alter with age. The structure, function and attachments of the collagen fibre system in human TMJ disc, differ according to the regions of the disc as shown under the polarised microscope [16]. Degradation can be observed in severely deformed TMJ discs. This is defined as a fissure of the disc covered with 
Table 1. Comparison of the immune reactivity in mice samples

\begin{tabular}{|c|c|c|c|c|c|c|c|c|}
\hline \multirow[b]{2}{*}{ TMJ } & \multirow[b]{2}{*}{ Intensity } & \multicolumn{2}{|c|}{ Young group } & \multicolumn{2}{|c|}{ Old group } & \multicolumn{2}{|c|}{ Total } & \multirow[b]{2}{*}{$\mathbf{P}$} \\
\hline & & n & $\%$ & $\mathrm{n}$ & $\%$ & $\mathbf{n}$ & $\%$ & \\
\hline \multirow[t]{2}{*}{ Type I collagen } & + & 0 & 0.0 & 7 & 100.0 & 7 & 100.0 & \multirow{2}{*}{$0.001^{*}$} \\
\hline & +++ & 7 & 100.0 & 0 & 0.0 & 7 & 100.0 & \\
\hline \multirow[t]{2}{*}{ MMP-2 } & ++ & 0 & 0.0 & 7 & 100.0 & 7 & 100.0 & \multirow{2}{*}{$0.001^{*}$} \\
\hline & +++ & 7 & 100.0 & 0 & 0.0 & 7 & 100.0 & \\
\hline
\end{tabular}

*Distribution is statistically significant; Fisher Exact test; $\alpha=0.05$; TMJ — temporomandibular joint; MMP-2 — matrix metalloproteinase-2

Table 2. Matrix metalloproteinase-2 (MMP-2) H-score comparisons of the young and old mice

\begin{tabular}{lcccc}
\hline TMJ & Young group $(\mathbf{n}=\mathbf{7})$ & Old group $(\mathbf{n}=\mathbf{7})$ & $\mathbf{t}$ & $\mathbf{p}$ \\
\hline MMP-2 & $186.17 \pm 17.38$ & $167.17 \pm 6.21$ & 2.821 & $0.030^{*}$ \\
\hline
\end{tabular}

Data are shown as mean \pm standard deviation (SD). *Distribution is statistically significant; Fisher Exact test; $\alpha=0.05$; TMJ — temporomandibular joint
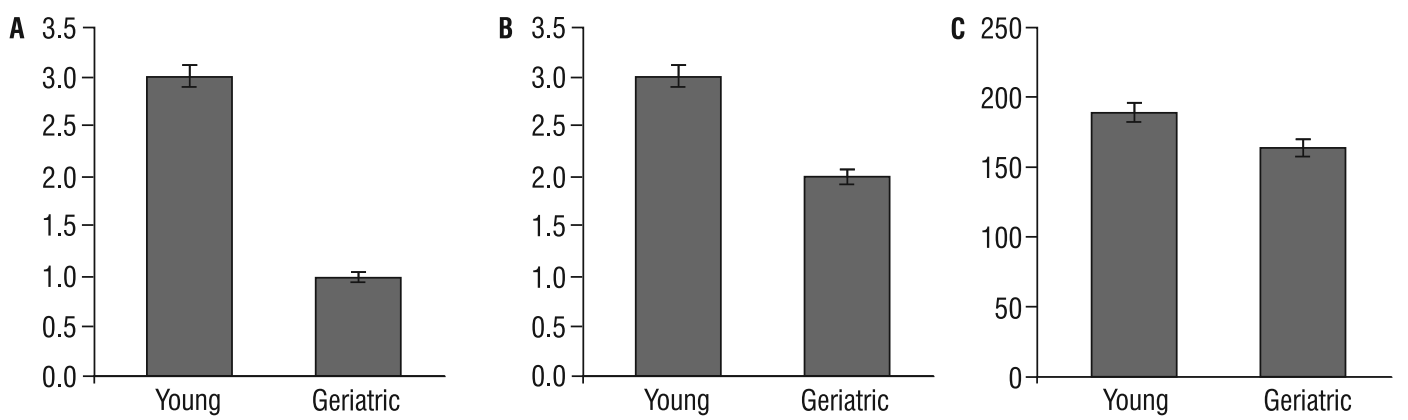

Figure 3. Matrix metalloproteinase-2 (MMP-2) H-score comparisons of the young and geriatric mice; A. Type I collagen; B. MMP-2; C. Temporomandibular MMP-2.

a layer of cells [10]. Middle, posterior, and anterior parts of the disc are avascular, excluding the posterior (bilaminar region) and anterior disc attachments [13]. Histopathological evaluations of our study showed that collagen bundles were located in a sagittal and oblique matter in young mice and composed of layers of compact collagen bundles alternately placed with each other. In the discs of the old mice, collagen bundle disruption was commonly observed, but in some disc regions, ruptures were also found. In the young mice, blood vessels were discernible, while in old mice; less blood vessels, structural degenerations, and dilatation in arterial and venules were detected. In young mice, the joint surface was unimpaired with a smooth outline. Conversely, the joint surface was deteriorated and, possibly due to calcification, lacerations were observed in the old mice. The joint surface in the young mice displayed a wavy semblance and beneath that surface, differentiated fibroblasts were found. Moreover, oval cells showed a sporadic and disorganised dispersion. In old mice, on the other hand, fissures were identified extending from the joint surface to the cartilage layer. Furthermore, the deep layers near the calcified cartilage were degenerated. In addition, notable proliferation in the cartilage margin, in the joint cartilage, disassociations and detachments with calcified strata devolved, attracted attention. TMJ is comprised of mandibular condyle, joint disk and glenoid fossa [18]. Mandibular condyle arthritic fibrocartilage, which is called secondary type cartilage, includes fibrous tissue and cartilage that contributes to elasticity [17]. Collagen fibres, which are found in the matrix of joint cartilage, are not elastic, yet they are more durable than steel due to their molecular arrangement. The morphologically thick and wavy structure of collagen fibres enhances its functional effectiveness. The H\&E stainings, in this study, showed abundant collagen fibres in the joint cartilage of the TMJ. In the young mice, a more dense and 
compact collagen layer was observed. It is known that TMJ, which has a fibrocartilaginous cartilage structure, is mostly comprised of type II collagen; however, in our immunostaining, the type I collagen protein was also intensively observed and that type I collagen immunoreactivity was found significantly higher in young mice than in old mice. Type I collagen fibres in fibrous cartilage are coarse, thick and resistant to tensile forces. Since TMJ has a fibrous cartilage structure, we investigated type I collagen here, and found that decreasing of type I collagen with ageing may be the cause of decreased tensile strength and also resistance to chewing forces. TMJ functions as the weight bearing diarthrodial joint during chewing and its constant usage and stress may lead to its degeneration in later ages [7]. In this study, the type I collagen immune reactivity was found higher in young mice; however, in old mice it was found higher and scattered in the extracellular space. Namely, with ageing, collagen proteins degenerate and appear in the extracellular space, less functional. Matrix metalloproteinases, a group of enzymes that work in harmony with many extracellular matrix proteins, are responsible for degradation during organogenesis, growth and tissue transformation. The release and activation of MMPs from adult tissue is limited, nevertheless, a marked increase is observed in various tissue pathologies, such as inflammatory diseases, tumour growth and metastasis, which involve undesired tissue destruction. Therefore, MMPs are also referred to as the hydrolysis components of the matrix and extracellular matrix [2]. In this study, MMP-2 immune reactivity showed positive staining. While it was intense $(3+)$ in young mice, it was average $(2+)$ in old mice. The $\mathrm{H}$-score evaluations displayed a significant higher cellular MMP- 2 immune reactivity in young mice. This decrease in MMP-2 concentrations due to ageing and continuous use in our experimental animals that do not carry any pathological conditions can be interpreted as a result of a decrease in organogenesis and the appearance of tissue damage.

\section{CONCLUSIONS}

Consequently, ageing is a natural course of development of severe TMJ disorders owing to the degenerations in the collagen structure and decrease in the MMP concentrations.

\section{REFERENCES}

1. Betts NJ, Barber HD. The Pathophysiology of Aging, Fonseca RJDavis WH (Ed.): Reconstructive Preprosthetic Oral and Maxillofacial Surgery. W.B. Saunders Co, Philadelphia 1995: 10-13.

2. Brinckerhoff $C E$, Matrisian LM. Matrix metalloproteinases: a tail of a frog that became a prince. Nat Rev Mol Cell Biol. 2002; 3(3): 207-214, doi: 10.1038/nrm763, indexed in Pubmed: 11994741.

3. Cahlin BJ, Dahlström L. No effect of glucosamine sulfate on osteoarthritis in the temporomandibular joints--a randomized, controlled, short-term study. Oral Surg Oral Med Oral Pathol Oral Radiol Endod. 2011; 112(6): 760-766, doi: 10.1016/j.tripleo.2011.06.012, indexed in Pubmed: 22001199.

4. Celenligil H; Yaşlıda Diş Hastalıktan. Kutsal YG-Çakmakçı M- Ünal S (Ed, ) Geriatri. Hekimler Yayın Birliği Ankara. 1997; 2: 815-837.

5. Dym $\mathrm{H}$, Israel $\mathrm{H}$. Diagnosis and treatment of temporomandibular disorders. Dent Clin North Am. 2012; 56(1): 149-61, ix, doi: 10.1016/j.cden.2011.08.002, indexed in Pubmed: 22117948.

6. Griffiths R. Report of the President's conference on the examination, diagnosis, and management of temporomandibular disorders. J Am Dent Assoc. 1983; 106(1): 75-77, doi: 10.14219/jada. archive.1983.0020.

7. Ishizuka $Y$, Shibukawa $Y$, Nagayama $M$, et al. TMJ degeneration in SAMP8 mice is accompanied by deranged Ihh signaling. J Dent Res. 2014; 93(3): 281-287, doi: 10.1177/0022034513519649, indexed in Pubmed: 24453178.

8. Kanter M. Protective effects of thymoquinone on the neuronal injury in frontal cortex after chronic toluene exposure. J Mol Histol. 2011; 42(1): 39-46, doi: 10.1007/s10735-010-9305-3, indexed in Pubmed: 21120684.

9. Katz RV, Meskin LH. The Epidemiology of Oral Diseases in Older Adults. Holm-Pedersen P-Löe H (Ed.): Old Dentistry. A Textbook of Oral Gerontology. Munksgaard. 1986: 221-237.

10. Kurita K, Westesson PL, Sternby NH, et al. Histologic features of the temporomandibular joint disk and posterior disk attachment: comparison of symptom-free persons with normally positioned disks and patients with internal derangement. Oral Surg Oral Med Oral Pathol. 1989; 67(6): 635-643, indexed in Pubmed: 2740089.

11. Odabas B, Aslan SG. Temporomandibular Eklem Anatomisi ve Rahatsızlıkları. Dicle Tıp Dergisi. 2008; 35: 77-85.

12. Ozden AN, Ersoy AE, Kisnisci RS. Clinical aspects of temporomandibular disorders. Turk J. Med Sci. 2000; 30: 77-81.

13. Paegle DI, Holmlund AB, Hjerpe A. Matrix glycosaminoglycans in the temporomandibular joint in patients with painful clicking and chronic closed lock. Int J Oral Maxillofac Surg. 2003; 32(4): 397-400 , doi: 10.1054/ijom.2003.0375, indexed in Pubmed: 14505623.

14. Piecuch JF. Oral and Maxillofacial Surgery for the Old Patient. Holm-Pedersen P-Löe H (Ed.): Old Dentistry. A Textbook of Oral Gerontology. Munksgaard, Copenhagen. 1986: 307-320.

15. Rantala MAl, Ahlberg J, Suvinen TI, et al. Temporomandibular joint related painless symptoms, orofacial pain, neck pain, headache, and psychosocial factors among non-patients. Acta Odontol Scand. 2003; 61(4): 217-222, indexed in Pubmed: 14582589.

16. Scapino RP, Obrez A, Greising D. Organization and function of the collagen fiber system in the human temporomandibular joint disk and its attachments. Cells Tissues Organs. 2006; 182(3-4): 201-225, doi: 10.1159/000093969, indexed in Pubmed: 16914922

17. Shibata S, Fujimori T, Yamashita Y. An in situ hybridization and histochemical study of development and postnatal changes of mouse mandibular angular cartilage compared with condylar cartilage. J Med Dent Sci. 2006; 53(1): 41-50, indexed in Pubmed: 16722144.

18. Tanaka S, Kuwahara S, Nishijima K, et al. Morphometric comparison of the rat mandible in F344 substrains, F344/Du and F344/N. Exp Anim. 2006; 55(5): 433-438, indexed in Pubmed: 17090959.

19. Warren MP, Fried JL. Temporomandibular disorders and hormones in women. Cells Tissues Organs. 2001; 169(3): 187-192, doi: 10.1159/000047881, indexed in Pubmed: 11455113. 